\title{
Wafer-level Fabrication of Ball Lens by Cross-cut and Reflow of Wafer-bonded Glass on Silicon
}

\author{
Dong-Whan Lee, Jin-Kyung Oh, Jun-Seok Choi, and Hyung-Jong Lee* \\ Department of Physics, Chonnam National University, Gwangju 500-757, Korea \\ Woo-Nam Chung \\ Department of Mechanical Engineering, Chonnam National University, Gwangju 500-757, Korea
}

(Received April 13, 2010 : revised May 13, 2010 : accepted May 20, 2010)

\begin{abstract}
Novel wafer-level fabrication of a glass ball-lens is realized for optoelectronic applications. A Pyrex wafer is bonded to a silicon wafer and cross-cut into a square-tile pattern, followed by wet-etching of the underlying silicon. Cubes of Pyrex on the undercut silicon are then turned into ball shapes by thermal reflow, and separated from the wafer by further etching of the silicon support. Radial variation and surface roughness are measured to be less than $\pm 3 \mu \mathrm{m}$ and $\pm 1 \mathrm{~nm}$, respectively, for ball diameter of about 500 $\mu \mathrm{m}$. A surface defect on the ball that is due to the silicon support is shown to be healed by using a silicon-optical-bench. Optical power-relay of the ball lens showed the maximum efficiency of $65 \%$ between two single-mode fibers on the silicon-optical-bench.
\end{abstract}

Keywords: Micro, Lens, Ball, Glass, Borosilicate

OCIS codes : (350.3950) Micro-optics; (130.0130) Integrated optics; (220.4000) Microstructure fabrication; (220.3630) Lenses; (060.0060) Fiber optics and optical communications

\section{INTRODUCTION}

Recent optical packaging on a planar platform such as a transmitter/receiver optical sub-assembly (TOSA/ROSA) using a silicon optical bench (SiOB) [1-2] or an optical switch array using MOEMS (micro-opto-electro-mechanical system) [3] integrates many edge-emitting optical components on wafer-level, such as optical waveguides, optical fibers, or LDs (laser diode). In such packaging, a ball lens is one of the crucial elements relaying light between the edgeemitting components. To date, various ways of producing a micro lens at wafer-level such as thermal reflow of photoresist [4], glass [5], sol-gel glass [6], vacuum-reflow of glass [7], or molding [8,9], have been reported. However, most of these methods produce hemispherical lenses relaying light normal to the wafer, in other words, to surface-sensitive devices such as PDs (photodiode) or VCSELs (vertical cavity surface emitting laser) that are attached to the wafer.

A micro-lens for an edge-emitting optical device is commonly spherical. It was developed extensively for TO-can (transistor outlook) packaging of LDs and PDs, and is produced mostly by glass melting in carbon powder or glass dropping in a furnace followed by polishing in an abrasive-filled rotating barrel [10-11]. However, these methods require considerable effort due to the individual nature of preparation, although some processes are done in batch.

On the other hand, wafer-level packaging of optoelectronic devices such as $\mathrm{SiOB}$ can produce thousands of chips per wafer with small foot-prints. Therefore, multiple thousands of ball lenses must be incorporated in packaging of a single wafer [2, 12], and a more efficient way of producing the ball lenses aligned on a platform is necessary for wafer-level packaging of edge-emitting devices.

Recently, Hsiharng et al. reported a mushroom-shaped micro-lens using a double-layered polymer [13, 14]. This seems to match the wafer-level packaging of edge-emitting devices. However, glass provides better mechanical, thermal, and chemical properties than the polymer. Therefore, various attempts to produce glass micro-lenses have been

\footnotetext{
*Corresponding author: hj_lee@chonnam.ac.kr

Color versions of one or more of the figures in this paper are available online.
} 
studied, although most of these methods produce hemispherical lenses[5-9]. Still, the mushroom-shaped or nearly spherical glass lens has not been reported, especially, for wafer-level application.

Borosilicate-based glass, for example, Pyrex (or Borofloat) draws special attention among various glasses as a lens material, because its match of thermal expansion to that of silicon enables wafer-bonding to silicon [15] or possibly to metal [16]. Therefore, its wafer-bonding to silicon[17] has been studied widely in MEMS or multi-level electronic packaging. However, precise micro-spherical fabrication of borosilicate-based material on the wafer-level is very difficult, because it contains alkalides such as sodium that prohibit dry etching. Wet etching can be an alternative to some extent [18], but it is difficult to control the shape of etching. Therefore, another way of processing the wafer-bonded Pyrex on silicon, for example, the division of Pyrex into small cells for lens formation is necessary.

In this study, we investigated wafer-level fabrication of ball lenses by cross-cut and reflow of wafer-bonded glass on silicon. We adopted precision grooving, instead of etching, for division of the lens cells. In section II, we introduce the fabrication procedures. In section III, we discuss the characteristics of the ball lens. Healing of the surface defect on the ball surface that results from silicon support during the reflow is also discussed. In section IV, application of the ball lens to optical packaging is demon- strated on SiOB platform. Finally, conclusions are presented in section $\mathrm{V}$.

\section{FABRICATION}

Fabrication procedures of micro-ball lens are illustrated in Fig. 1. Pyrex wafer (Corning 7740) with thicknesses of $500 \mu \mathrm{m}$ is chosen as a lens material. Pyrex has a strain point of $510^{\circ} \mathrm{C}$, annealing point of $560^{\circ} \mathrm{C}$, softening point of $821^{\circ} \mathrm{C}$, melting point of $1251^{\circ} \mathrm{C}$, and its thermal expansion coefficient of $3.2 \times 10^{-6} /{ }^{\circ} \mathrm{C}$ matches that of silicon.

Firstly, a silicon nitride layer with thickness of $300 \mathrm{~nm}$ is deposited onto a silicon wafer. Then, a Pyrex wafer is cleaned using piranha solution (the mixture of $1 \mathrm{H}_{2} \mathrm{SO}_{4}$ and $2 \mathrm{H}_{2} \mathrm{O}_{2}$ in volume) and dehydrated on a hot plate at $120^{\circ} \mathrm{C}$ for $30 \mathrm{~min}$. The prepared Pyrex is put on to the silicon wafer and bonded at $450^{\circ} \mathrm{C}$ for $30 \mathrm{~min}$, applying $300 \mathrm{~V}$ to the silicon substrate. Secondly, the bonded wafer is grooved into cross-stripe patterns, cutting fully through the Pyrex part by using a dicing saw. Nominal positioning accuracy of the dicing machine is $0.1 \mu \mathrm{m}$. The grooved wafer is then cleaned in an ultrasonic bath by BOE (Buffered Oxide Etch) solution for $5 \mathrm{~min}$., eliminating from its surface particulates generated during the grooving. The bottom silicon of the grooved wafer is etched to reduce the bottom

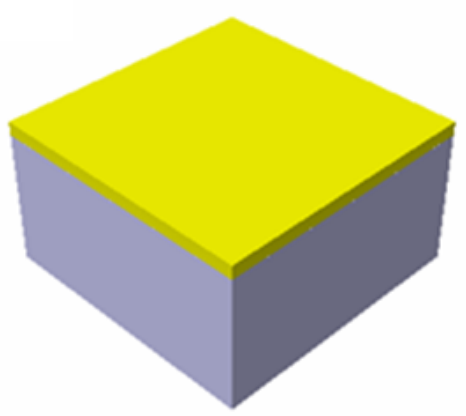

(a)

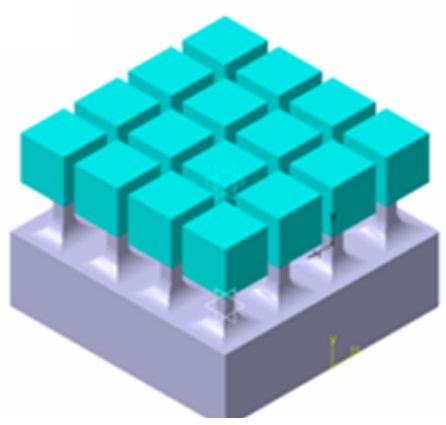

(d)

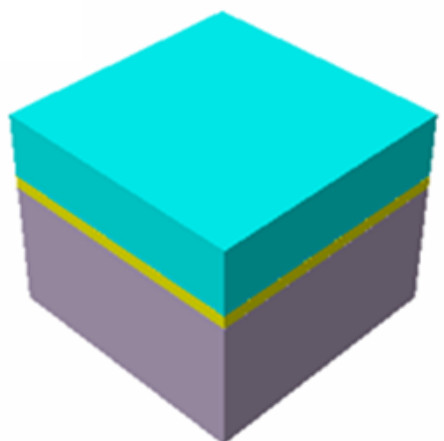

(b)

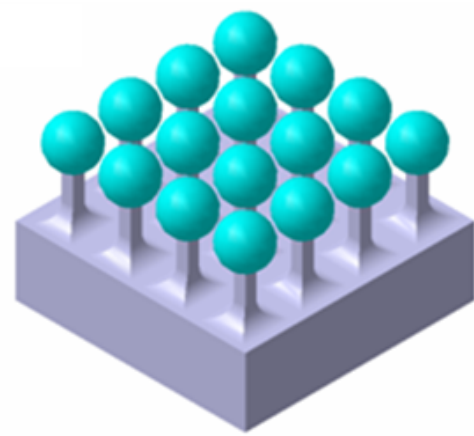

(e)

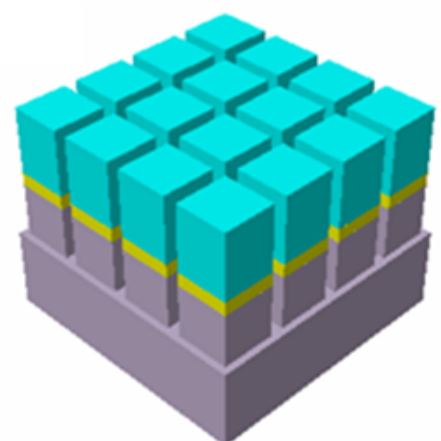

(c)

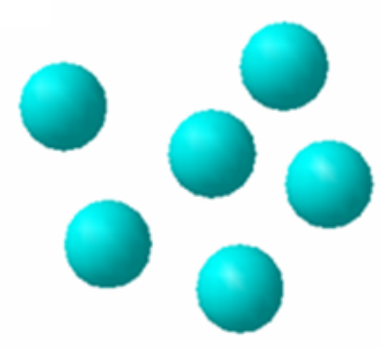

(f)

FIG. 1. Fabrication procedure of micro-ball lens: (a) Deposition of $\mathrm{Si}_{3} \mathrm{~N}_{4}$ layer, (b) Bonding of Pyrex to $\mathrm{Si}_{3} \mathrm{~N}_{4} / \mathrm{Si}_{\text {substrate, (c) cutting }}$ of Pyrex into Si substrate in square-tile pattern, (d) etching of Si substrate, (e) thermal reflow of Pyrex, and (f) separation of micro-ball lens. 


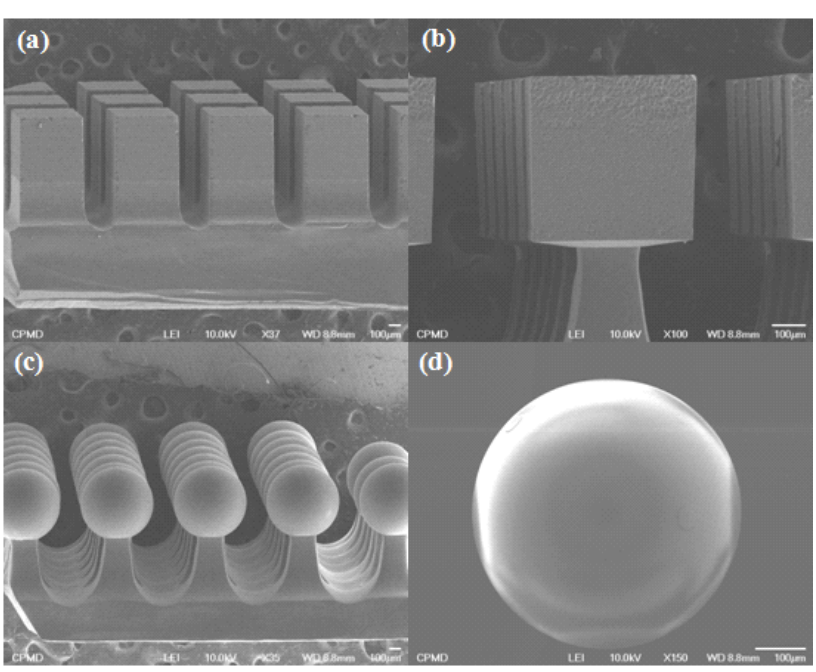

FIG. 2. SEM images of (a) grooved cells, (b) cube cells, (c) reflowed spheres on etched silicon columns, and (d) separated ball-lens.
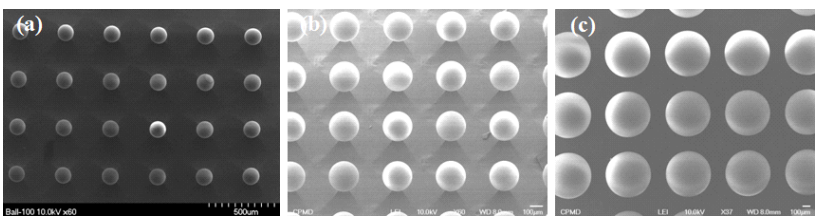

FIG. 3. Ball lenses with various diameters: (a) $d=97 \mu \mathrm{m}$, (b) $d=232 \mu \mathrm{m}$, and (c) $d=530 \mu \mathrm{m}$.

contacts of the diced cells, using silicon etchant of $\mathrm{HF}$ : $\mathrm{HNO}_{3}: \mathrm{H}_{2} \mathrm{O}$ (4: $4: 2$ in volume).

Finally, the etched wafer is heated in a nitrogen-ambient furnace at $850^{\circ} \mathrm{C}$ for $20 \mathrm{~min}$., shaping the Pyrex cubes on the silicon supports into ball shapes by thermal reflow. This shaping is associated with the surface tension of reflowed glass. In other words, the viscous glass-cell releases and minimizes its surface energy to reach its minimum energy for equilibrium. The ball spheres produced are then cleaned in BOE and separated from the wafer by etching further the silicon supports. In the cleaning procedure, the nitride on the ball is also removed.

We examined the volume change of the Pyrex cell in each step of the fabrication processes. BOE cleaning after grooving and reflow showed no measurable changes. However, undercut etch of silicon supports, as shown in the Fig. 2(b), showed slight decrease of cell volume. The grooved cube with the dimension of $416 \times 416 \times 504 \mu \mathrm{m}$ is decreased to $403 \times 403 \times 490 \mu \mathrm{m}$ during the etch. Fig. 3 shows the ball lenses produced with various diameters from several tens to hundreds of micron.

\section{MEASUREMENTS}

To evaluate the angular variation of radius, the contour

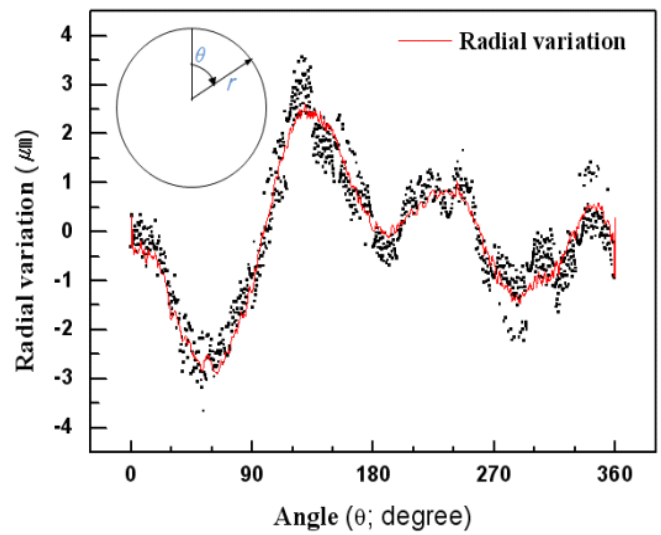

(a)

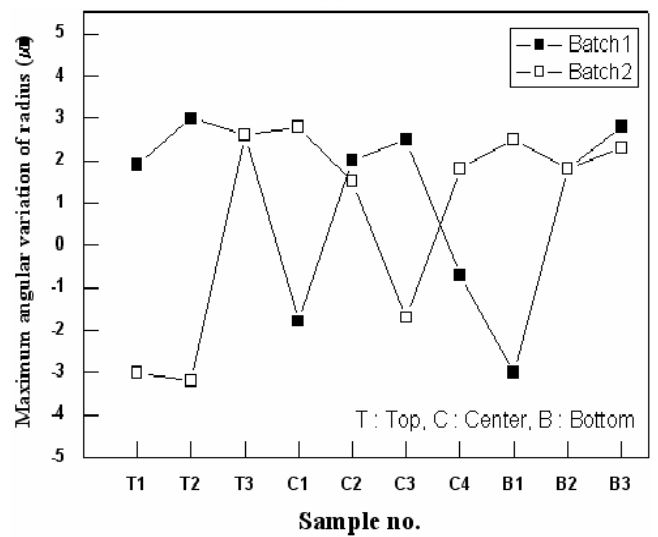

(b)

FIG. 4. Characterization of ball lens: (a) Angular variation of ball radius as measured from its best-fit center and (b) uniformity of angular variation of ball radius in wafer.

and its best-fit center is extracted from the digitized SEMimage of a ball sphere using image-processing software. The angular average of the diameter is measured to be 536 $\mu \mathrm{m}$ for the horizontal and $537 \mu \mathrm{m}$ for the vertical crosssection of the sphere, respectively, on the wafer. Accordingly, the measurement by SEM-image showed good agreement with the diameter of $534 \mu \mathrm{m}$ as predicted from the cube image assuming no volume change. Therefore, we can consider that there is no appreciable change in the cell volume during the reflow. Considering the volume change of the cube cell that occurs during the etching of the supporting silicon, we believe that a diameter control of less than $5 \mu \mathrm{m}$ is easily achievable.

Fig. 4(a) shows the angular variation of ball radius as measured from its best-fit center. We observed the radial variation of less than $\pm 3 \mu \mathrm{m}$. The distribution band of about $\pm 0.7 \mu \mathrm{m}$ in the measured points of Fig. 4(a) represents the error due to the pixel size of $0.625 \mu \mathrm{m}$ in the image. Therefore, the band seems to have no relation to the roughness of the sphere. Averaged radius for the band is represented as a solid line in Fig. 4(a). Repeated measurements of this angular variation of radius for 20 balls from two batches, 10 points each on a wafer, as shown in Fig. 4(b), shows 
no appreciable variation (less than $\pm 3 \mu \mathrm{m}$ ).

We analyzed the surface of the ball by using a threedimensional (3d-) profiler (New View 6000 of Zygo Corp.). Fig. 5(a) shows the geometric 3d-profile of the ball sphere. Fig. 5(b) shows the cross-sectional profile along $\mathrm{x}$ - and $y$-axis of Fig. 5(a). We calculated the radius of the ball from the cross-sectional profile of Fig. 5(b), using the following simple geometric equation.

$$
\mathrm{R}=\mathrm{L}^{\mathrm{z}} / 8 \mathrm{~B},
$$

where $\mathrm{L}$ is the width of the base and $\mathrm{B}$ is the maximum height from base level. Estimated radii show $270 \mu \mathrm{m}$ and $269 \mu \mathrm{m}$, respectively, along the $\mathrm{x}$ - and $\mathrm{y}$-axis.

In Fig. 5(c), the height variation from a presumed reference of spherical surface is shown as a color contour. The reference sphere in the measurement of Fig. 5(c) is determined from the 2D data of Fig. 5(a) based on the

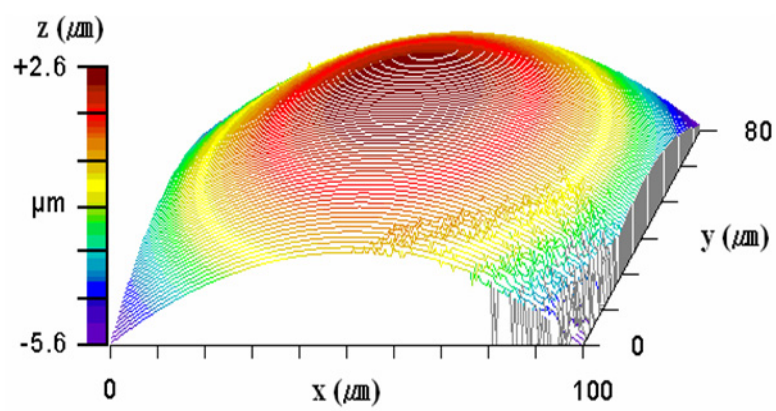

(a)

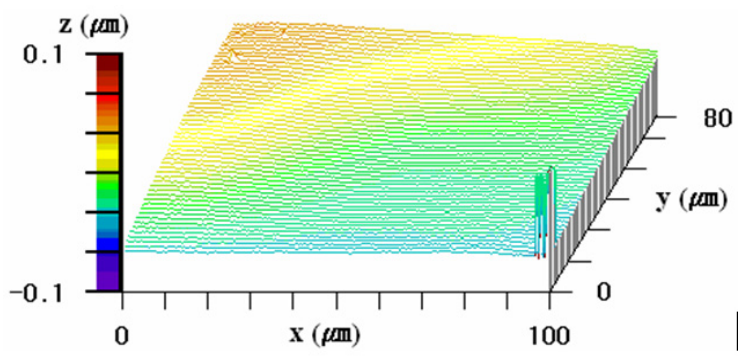

(c) least-square-fit of the measured surface. The height variation in the fitted surface shows less than $0.1 \mu \mathrm{m}$. Comparing this with the measured $\pm 3 \mu \mathrm{m}$ from the SEM image (Fig. 4), the global variation of radius in Fig. 4 is much larger than the local variation in the Fig. 5(c). This difference comes from the localization in the fitting. Therefore, we can expect that the effective NA (numerical aperture) of an incoming ray toward the ball lens determines the focusing quality of the lens. Fig. 5(d) shows the surface roughness of the ball lens. It shows a surface smooth enough to be used for optical elements as rough as $\pm 1 \mathrm{~nm}$. We used a high-pass filtering of the 2D data of Fig. 5(c) in acquiring Fig. 5(d).

Formation of a ball lens on a column support usually produces a stem-print on its surface when the ball is separated from the support. Fig. 6(a) and 6(b) show a stem-print on the surface. This print is due to masking of supporting silicon during the thermal reflow, and is inscribed

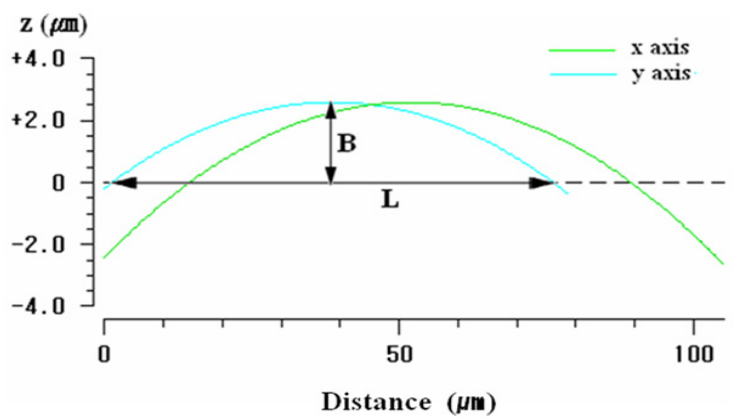

(b)

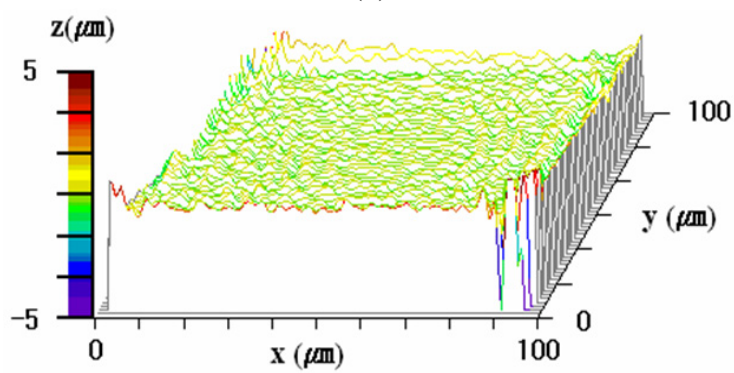

(d)

FIG. 5. Surface measurements by 3d-profiler: (a) 3d-view of ball sphere, (b) cross-sectional profiles along $x$ - and y-axis, (c) radius variation as measured from least-square-fitted spherical surface, and (d) surface roughness as obtained by high-pass filtering of (c).
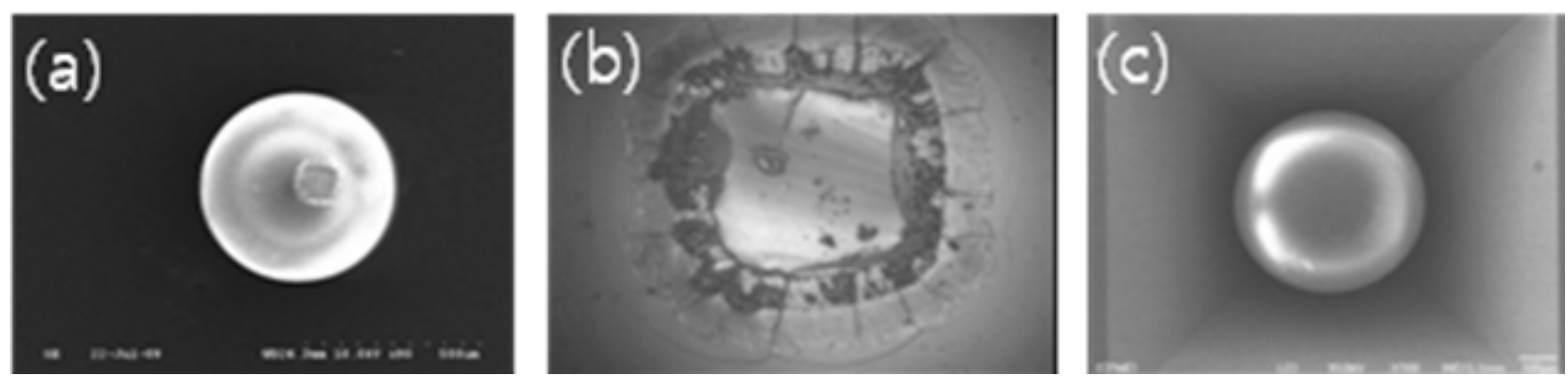

FIG. 6. SEM images of (a) silicon-support stem-print on ball sphere, (b) enlarged view of stem-print, and (c) reflowed surface in a pit of SiOB. 


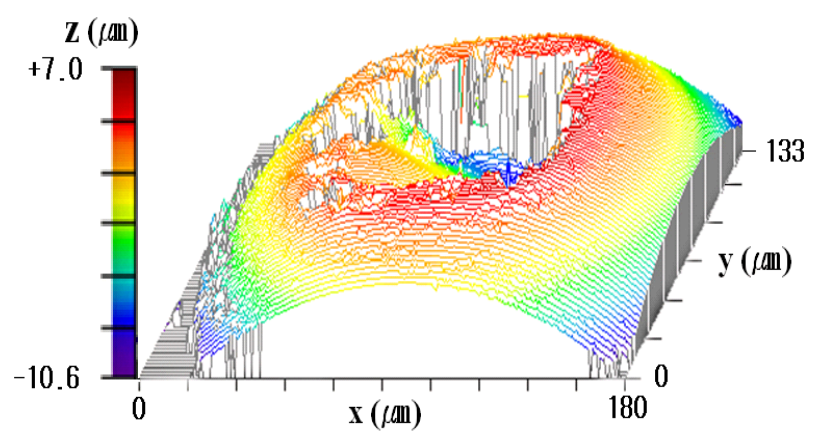

(a)

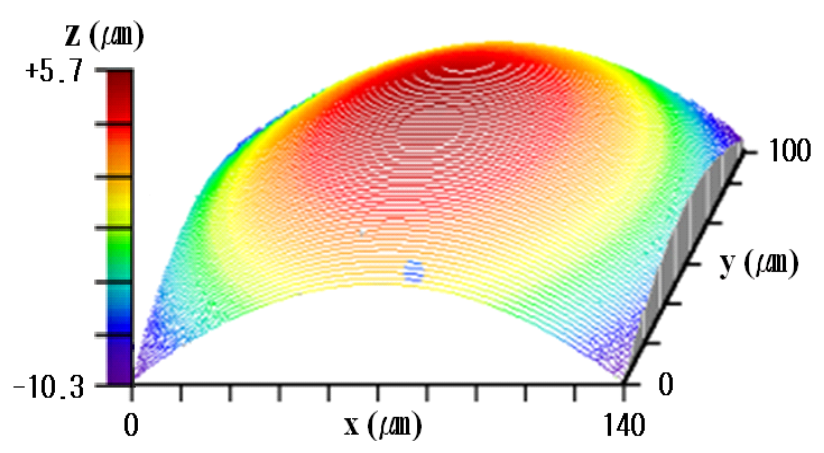

(c)

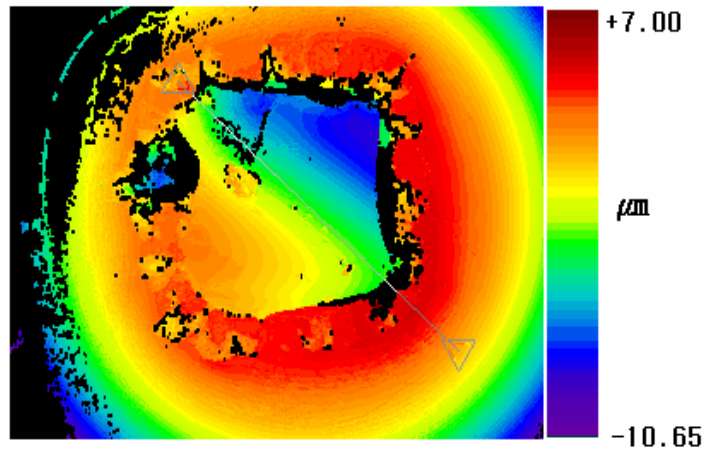

(b)

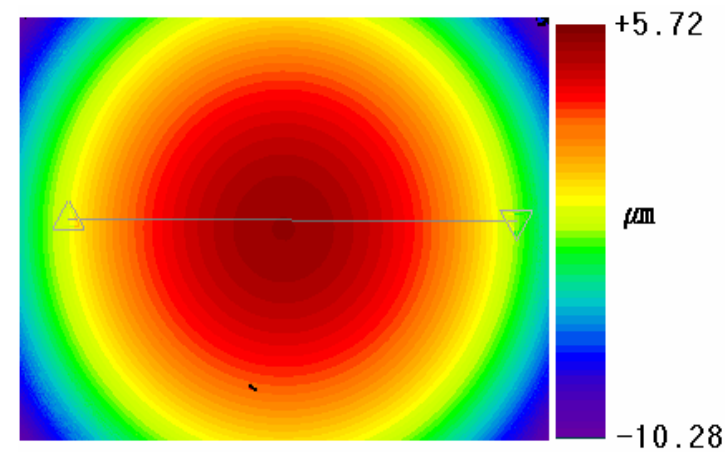

(d)

FIG. 7. Surface measurements by 3d-profiler: (a) $3 d$ view and (b) $2 d$ contour of stem-print on ball sphere, and (c) $3 d$ view and (d) $2 d$ contour of reflowed surface.

into the ball surface when it is seperated from the supporting silicon. Such a print must be healed for the ball to be used as an optical element. Therefore, we tried to smooth the stem-print by additional thermal reflow. The reflow of the ball was carried out in a four-surface pit of a silicon-based optical bench [1], which is commonly used in optoelctronic packaging using a ball lens.

Fig. 6(c) shows SEM image of ball sphere reflowed in a pit of $\mathrm{SiOB}$ at $950^{\circ} \mathrm{C}$ for $20 \mathrm{~min}$. We observed no apparent stem-print on the ball surface after the reflow. It is worth while to mention that the proper procedure of reflow also fixes the ball lens into the pit of SiOB without using any adhesive.

Fig. 7(a) and 7(b) show the $3 d$ view and $2 d$ contour of the stem-print on a ball sphere, and Fig. 7(c) and Fig. 7(d) show the $3 \mathrm{~d}$ view and $2 \mathrm{~d}$ contour of the reflowed stemprint. The roughness of reflowed surface is analyzed by using the data of Fig. 7(c) as is done in the case of Fig. 5(d). It shows the roughness of $\mathrm{ra}=3 \mathrm{~nm}$. This shows that reflow in a pit of SiOB produces a surface smooth enough to be used for optical applications.

Fig. 8 shows the uniformity of ball-surface roughness after reflow. We repeated this measurement for 20 balls from two batches, 10 points each on a wafer. Fig. 8 shows no appreciable roughness - less than $10 \mathrm{~nm}$.

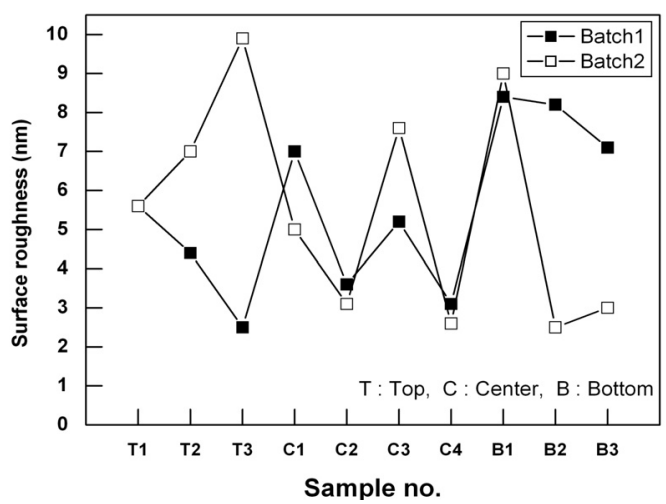

FIG. 8. Uniformity of ball-surface roughness.

\section{OPTICAL ALIGNMENT ON A SILICON OPTICAL BENCH}

To test the use of our ball lens in the optical packaging of edge-emitting optical devices, we prepared an $\mathrm{SiOB}$ structure on (100) silicon surface, which is composed of one pyramid-shaped pit on a recessed terrace and two facing $\mathrm{V}$-grooves. The pyramid-shaped pit is used for fixing the ball lens. The two facing $\mathrm{V}$-grooves are used for fixing input and output fibers. Firstly, the ball lens is reflowed and fixed in the fit. Secondly, additional tuning of the fiber height was carried out by dry-etching the groove for 


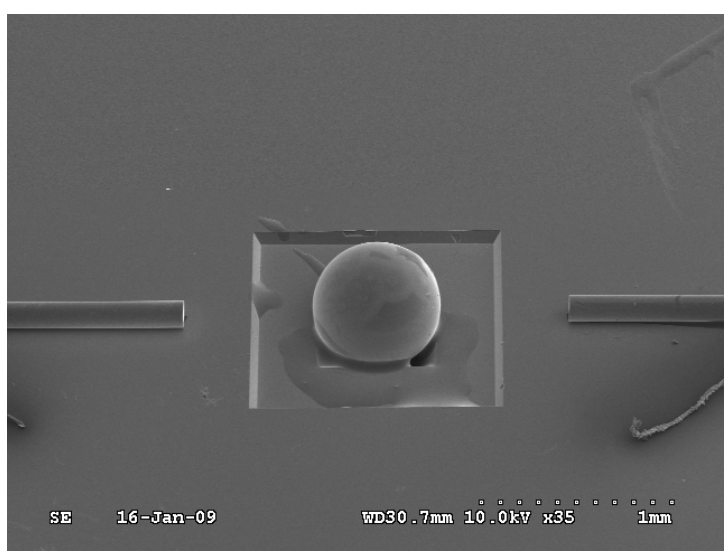

FIG. 9. Silicon optical bench with micro-ball lens aligning to two optical fibers.

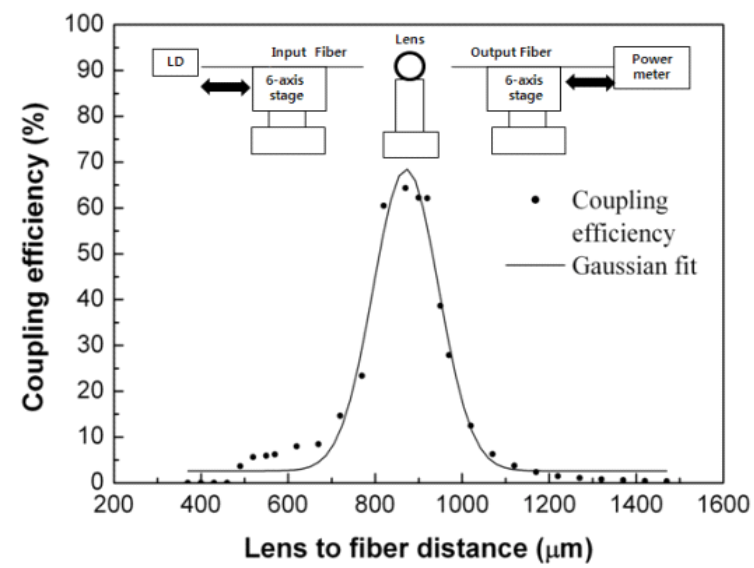

FIG. 10. Optical coupling of micro-ball lens on SiOB platform between two SMF fibers.

precise alignment along the vertical direction. We used SF6 for selectively etching the groove while keeping the ball in its height. The etch-rate of the Pyrex ball by the SF6 is negligible. Finally, the input and output optical fibers are fixed to the v-grooves as shown in Fig. 9.

Optical coupling of the assembled ball lens between two standard SMF's (single mode fiber) on the $\mathrm{SiOB}$ was examined. The diameter of the test ball-lens is $536 \mu \mathrm{m}$. The measured light wavelength is $1.31 \mu \mathrm{m}$. Pyrex has the refractive index of 1.473 for the wavelength. Fig. 10 shows the optical-couplings for distance steps of $25 \mu \mathrm{m}$ each along the axes of two measuring optical fibers. (The distance is measured from the lens center to the fiber end). Measurement shows maximum coupling of $65 \%$ at distance of $870 \mu \mathrm{m}$ as referenced to the physical contact of two measuring optical fibers.

On the other hand, the focal length formular of the ball lens,

$$
f=\frac{\mathrm{nR}}{2(n-1)}
$$

gives $417 \mu \mathrm{m}$. Therefore, we can expect that the optimum coupling occurs at $834 \mu \mathrm{m}$. This seems to be consistent when considering the one step distance is $50 \mu \mathrm{m}$.

Considering there are four glass-air interfaces between two optical fibers, the estimated reflection loss in the coupling is about $15 \%$. The remaining loss of $20 \%$ in the coupling is generally believed to come from the spherical aberration of the ball lens. This is typical when using a low index lens; it can be overcome by using higher index material as SF-glass.

\section{CONCLUSION}

A micro-ball lens is produced on wafer-level by using precision mechanical-grooving and thermal reflow. Ball spheres with diameters from tens to hundreds of microns are produced successfully. Radius variation of the lens in a batch is shown to be less than $3 \mu \mathrm{m}$. Radius variation within a sphere is shown also to be less than $3 \mu \mathrm{m}$. This result shows that the fabricated micro-ball lens has reasonably good sphericity compared to one (typically 1 $\mu \mathrm{m})$ produced by conventional methods. Stem-prints due to the silicon supports are shown to be eliminated by additional reflow in a $\mathrm{SiOB}$ pit. The lens also shows a surface smooth enough to be used for optical applications.

This procedure of producing ball lenses is believed to be promising, especially considering that it can produce millions of balls lenses on a single wafer and that it is compatible with optical packaging on a planar platform. Optical coupling of the ball lens is tested between two SMF fibers on a SiOB. Maximum coupling efficiency of $65 \%$ is achieved.

\section{ACKNOWLEDGMENT}

This study was financially supported by Chonnam National University, 2004.

\section{REFERENCES}

1. J. Gates, D. Muehlner, M. Cappuzzo, M. Fishteyn, L. Gomez, G. Henein, E. Laskowski, I. Ryazansky, J. Shmulovich, D. Syvertsen, and A. White, "Hybrid integrated silicon optical bench planar lightguide circuits," in Proc. Electronic Components and Technology Conference (Seattle, WA, USA, May 1998), pp. 551-559.

2. D. W. Sherrer, N. Brese, J. Fisher, C. Gaebe, N. A. Heiks, J. Getz, J. Rasnake, and E. S. Simon, "Wafer-level packaging technology for 10Gbps TOSAs," in Proc. Electronic Components and Technology Conference (Lake Buena Vista, FL, USA, May 2005), pp. 1325-1332.

3. L.-S. Huang, S.-S. Lee, E. Motamedi, M. C. Wu, and C.-J. Kim, "MEMS packaging for micro mirror switches," in 
Proc. Electronic Components and Technology Conference (Seattle, WA, USA, May 1998), pp. 592-597.

4. Z. D. Popovic, R. A. Sprague, and G. A. N. Connell, "Technique for monolithic fabrication of microlens arrays," Appl. Opt. 27, 1281-1284 (1988).

5. S.-K. Lee, M.-G. Kim, K.-W. Joo, S.-M. Shin, and J.-H. Lee, "A glass reflowed microlens array on a Si substrate with rectangular through-holes," J. Opt. A: Pure Appl. Opt. 10, 1-7 (2008).

6. M. He, X.-C. Yuan, N. Q. Ngo, J. Bu, and V. Kudryashov, "Simple reflow technique for fabrication of a microlens array in solgel glass," Opt. Lett. 28, 731-733 (2003).

7. P. Merz, H. J. Quenzerl, H. Bemt, B. Wagner, and M. Zoberbier, "A novel micromachining technology for structuring borosilicate glass substrates," in Proc. Transducers 03, The 12th International Conference on Solid Stale Sensors, Actuators and Microsystems (Boston, MA, USA, Jun. 2003), pp. 258-261.

8. J. Albero, L. Nieradko, C. Gorecki, H. Ottevaere, V. Gomez, H. Thienpont, J. Pietarinen, B. Päivänranta, and N. Passilly, "Fabrication of spherical microlenses by a combination of isotropic wet etching of silicon and molding techniques," Opt. Exp. 17, 6283-6292 (2009).

9. D.-H. Cha, Y. Hwang, J.-H. Kim, and H.-J. Kim, "Transcription characteristics of mold surface topography in the molding of aspherical glass lenses," J. Opt. Soc. Korea 13, 213-217 (2009).

10. L. Hao, S. Bangren, W. Jijiang, G. Lijun, and L. Aimei, "Fabrication of gradient refractive index ball lenses using the method of combination of ion exchanging and sagging," Opt. Comm. 276, 310-316 (2007).

11. A. Yamagata, F. Ishizaki, and K. Sugizaki, "Globular glass manufacturing apparatus and method for manufacturing the globular glass," U.S. Patent 0132752 A1 (2005).

12. H. L. Althaus, W. Gramann, and K. Panzer, "Microsystems and wafer processes for volume production of highly reliable fiber optic components for telecom- and datacomapplication," IEEE Trans. on Components, Packaging, and Manufacturing Technology B21, 7-15 (1997).

13. H. Yang, C.-K. Chao, C.-P. Lin, and S.-C. Shen, "Microball lens array modeling and fabrication using thermal reflow in two polymer layers," J. Micromech. Microeng. 14, 277-282 (2003).

14. C.-T. Pan, C.-H. Chien, and C.-C. Hsieh, "Technique of microball lens formation for efficient optical coupling," Appl. Opt. 43, 5939-5946 (2004).

15. F. Pigeon, B. Biasse, and M. Zussy, "Low-temperature Pyrex glass wafer direct bonding," Electron. Lett. 31, 792-793 (1995).

16. G. Wallis and D. I. Pomerantz, "Field assisted glass-metal sealing," J. Appl. Phys. 40, 3946-3949 (1969).

17. M. Alexe and U. Gösele, Wafer Bonding, Application and Technology (Springer Verlag, Berlin, Germany, 2004).

18. M. Bua, T. Melvin, G. J. Ensell, J. S. Wilkinson, and A. G. R. Evans, "A new masking technology for deep glass etching and its microfluidic application," Sens. Actuators A 115, 476-482 (2004). 